\title{
Mechanism of Human Resource Management Practice Influencing Corporate Green Innovation Behavior - an Empirical Research Based on Manufacturing Enterprises
}

\author{
Yan GAO, Yingying ZHANG \\ Northwest University, Xi' an, China \\ nwyangao@126.com, 2645457215@qq.com
}

\begin{abstract}
With the intensification of global warming and ecological deterioration and other environmental problems, green innovation has become an important issue of manufacturing enterprises' management. Human resources management practice is an important support and protection to carry out green innovation activities for enterprises. This paper uses a variety of methods such as questionnaire survey, multivariate regression model to do empirical research on the mechanism of human resource management influencing corporate green innovation behavior. The results show: human resource management practices significant positively impact corporate green innovation behavior, based on mediating effect of organizational commitment of employees. In the research on five dimensions of human resource management, three hypothesized relationships verified, namely training, compensation and employee involvement. While hypothesized relationships of recruitment and performance has not been empirically supported. According to the results of the survey, we put forward some suggestions to promote the implementation of corporate green innovation behavior.
\end{abstract}

Keywords: Human Resource Management, Green Innovation Behavior, Multiple Regression.

\section{Introduction}

With the rapid growth of the global economy, the depletion of natural resources, the deterioration of the environment, the global green movement is on the rise since the 1990s.Manufacturing industry, as a pillar industry of the national economy in China's rapid economic development, has played a pivotal role. But the development model of rapid expansion has led to the rapid growth of resource consumption and pollutant emissions rising [13]. In order to deal with the problems of manufacturing industry, the enterprises must transform their operation system and take some green innovation. Green innovation refers to innovative activities that bring together new or improved ideas, products, processes, technologies and systems in economic activities to avoid or reduce the adverse impact on the environment, so that economic, environmental and social benefits are harmonized [4]. 
As the first resource, human resources are an important factor in the supply of innovation. The essence of innovation driven is the driving of talent. And green innovation-oriented human resource management practice is an important support and protection to promote enterprises carry out green innovation activities and enhance the green innovation performance. Therefore, it is helpful to promote the development of green innovation activities of manufacturing enterprises in China and promote the improvement of green innovation performance by exploring the green innovationdriven human resources management practice mechanism of manufacturing enterprises and developing reasonable human resource management plan and counter measures. At present, the research on green innovation behavior of manufacturing enterprises is still a frontier issue both at home and abroad. It mainly focuses on the research of green innovation performance in manufacturing industry. Such as the study on green innovation performance and differences of Chinese manufacturing enterprises [15], or the research on the impact of forward - looking environmental strategy on enterprise green innovation performance [5]. Many researchers the green innovation behavior from the perspective of green supply chain management $[14,11]$. There is little literature about the green innovation performance of manufacturing enterprises from the perspective of human resource management practice. Therefore, this paper uses a variety of methods such as questionnaire survey, multivariate regression model to do empirical research on the mechanism of human resource management influencing corporate green innovation behavior. It is of great theoretical and practical significance to discuss the implementation strategy of green human resource management and to create green atmosphere, protect the environment, enhance the green innovation performance and promote the sustainable development of enterprises.

\section{Literature overview and Theoretical Hypothesis}

\subsection{The Impact of HRM Practice on Green Innovative Behavior}

The human resource management of this research refers to human resource management practice recruitment, training, performance management, compensation administration, employee involvement [2]. Modern human capital theory holds that human capital is also corporate capital just same as material capital. People are the core capital of enterprises. The use and management of people can promote the success of corporate strategy. Enterprises in the recruitment process must pay attention to the candidate's green awareness, green ability and consciously obey the green rules of the enterprise. In the training of human resources management, the company should conduct the targeted training for employees, increase the content of green production and operations. Training methods with green innovation will guide the green thinking and behavior of employees. In the compensation administration, enterprises can increase salaries for employees' special green behavior. It may be non-monetary nature of the reward, which can inspire employees to practice green production behavior. In the performance evaluation, enterprises should focus on the green innovation behavior of individual employees. It will also stimulate the green 
behavior of employees. Creating and maintaining a pro-friendly working environment can encourage employees to create the greatest green innovation for their business. It is helpful to improve the green innovation that encourage employees to participate more strategic decision-making, and provide employees more participation. Therefore, this study suggest that it is not a single human resources management or a few modules, but the overall human resources management play an important role for the green innovation of enterprises. We therefore hypothesize as follows:

Hypothesis1: Human resource management practice has a significant positive impact on green innovation behavior

\subsection{The Influence of HRM Practice on Organizational Identity}

Human resources management is the link between the organization and the staff. Organization provide staffs job training, increase the job skills, get paid, promotion and achieve career goals through human resource management. So good human resources management can improve the organizational identity of the staff. Employees and organizations have a common green value of the pursuit by the management of employees, and ultimately get a deep sense of organizational identity. Thus, we posit the following:

Hypothesis2: Human resource management practice has a significant positive impact on organizational identity.

Hypothesis2a: Recruitment has a significant positive impact on organizational identity.

Hypothesis2b: Training has a significant positive impact on organizational identity. Hypothesis2c: Payment has a significant positive impact on organizational identity. Hypothesis2d: Employee participation has a significant positive impact on organizational identity.

\subsection{The Influence of Organizational Identity on Green Innovative Behavior}

American scholar Westbrook argues that individual's change in behavior is a process in which there are three stages: "knowledge", "emotion", "behavior" [10]. Cognition is the first variable of emotion, that is, the individual will nurse some feeling which is associated with external things and stimuli, and then individuals will do something about it. The stronger the organizational identity of the employees in the enterprise, the easier it is to recognize the values of the organization, the easier it is to be consistent with the organization in terms of speech and action, and to promote the maximization of organizational functions. When employees are committed to the green values, policies, institutions and practices of the business, employees will consciously engage in the work. Employees will take the initiative in the work of environmental awareness, environmental protection and environmental participation in the combination, thereby enhancing the enterprise's green innovation. 
Consequently, we hypothesize as follows: Hypothesis3: Organizational identity has a significant impact on green innovation behavior.

\subsection{Mediation role of organizational identification}

The results of the study on the role of human resources management, mainly concentrated in the field of environmental protection. In the study of corporate green behavior as an explanatory variable, the representative research is about the impact mechanism of green cognition and green emotion on green behavior in retail enterprises. The authors of this study are He Aizhong and Du Jing [3]. They use the structural equation model and other methods to verify their conclusions. This study validated that green cognition and green sentiment of retail enterprises have a significant positive impact on green behavior, and retail enterprises' green emotions play a part of mediating role in the positive effect of green cognition on green behavior. Employees are the object of human resource management practice and the impact of green cognition. Green behavior that was caused by green emotion is an employee role outside the behavior. But just as organization identity, green behavior is also recognized from the employees' heart. So, employees will work hard so that enterprises can achieve green innovation. Thus, we propose the following hypothesis:

Hypothesis 4: Human resource management practice through the organization of positive sense of the positive impact of green business innovation. 
$\mathrm{H} 1$

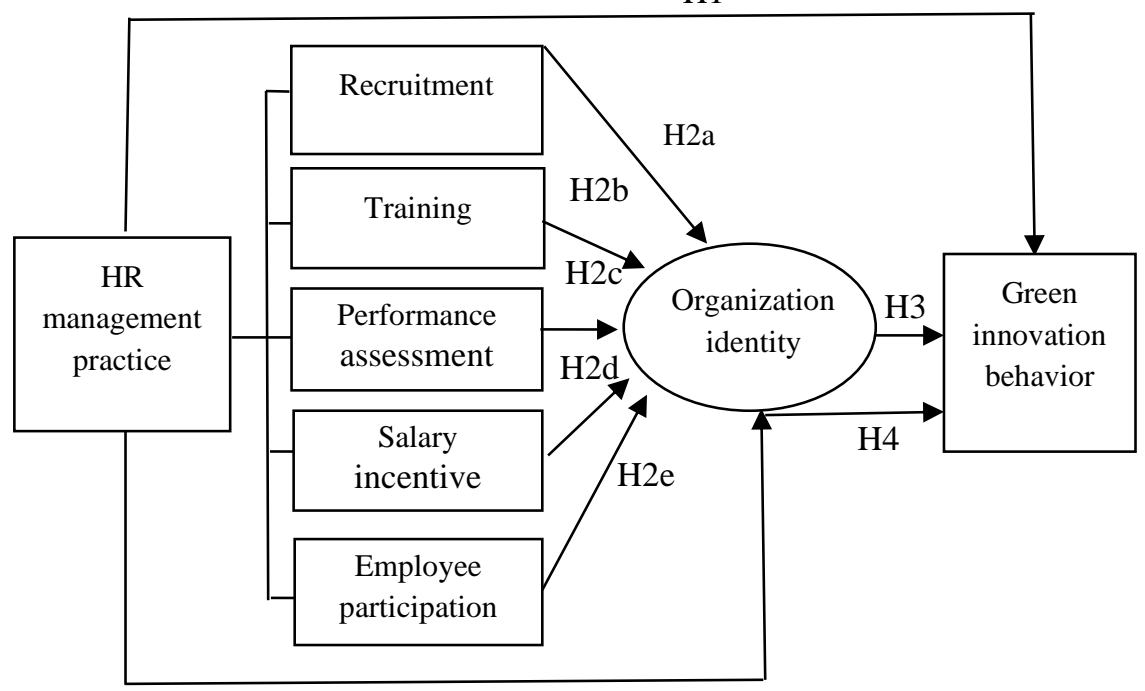

Fig. 1. The conceptual framework and research hypotheses

\section{Methods and results}

\subsection{Data collection and samples}

Data for this study were collected through a survey on the practice of human resources management and staff organizational identity. The research object of this study is manufacturing enterprises which had at least 10 years of operation period and had employees below 100 people. Because we use the matching questionnaire to collect the data, respondents were employees and senior managers. The questionnaire was revised on the original maturity scale.

We handed out 45 questionnaires to manufacturing enterprises. In order to avoid homology, the questionnaire survey was conducted by multivariate regression model. A total of 225 employees and 45 senior managers participated. After deleting unmatched data across the two surveys, our final sample include 157 A questionnaires and 42 B questionnaires. We used the Spss 19.0 to test the reliability. The result shows that the overall Cronbach's a coefficient of the scale is $0.82(>$ critical value 0.7$)$. This means the questionnaire has a better reliability. In terms of validity test, the scale adopted in this study is based on a large number of research results summed up and modified, and thus have a better content validity. 


\subsection{Measures}

All the measures of this research are based on the established scales. Questionnaire items were measured on a 5-point Likert scale in which " 1 " represents "strongly disagree" and "5" represents "strongly agree". For human resource management, we divided it five dimensions. We used different three items to measure the recruitment, training, salary, performance and employee participation. These items were according to the work of Yang Guang [12]. Based on the research of Judge and Douglas, seven items were adopted to measure the green innovation behavior. From the primary scale validated by Ashforth and Mael [1], we tested the organizational identity using four items. In this study, we set the control variables when we select the research objects, including the nature of the ownership of the enterprise, the number of enterprises, and the operation period of the enterprise.

\subsection{Reliability and validity of the model}

In the exploratory factor analysis, the total variance explanations were $84.35 \%$, $68.53 \%$ and $79.27 \%$ respectively, which were required to explain the requirements of human resource management practice, organizational identity and corporate green innovation. In this study, we validate the factor analysis of human resource management practice, organizational identity and green innovation. According to the criterion, the model is better. In the confirmatory analysis of organization identity, $\chi^{2}$ $\mathrm{P}$ is 0.879 , which is higher than 0.05 , which indicates that the model has high fitting degree, RMSEA is less than 0.05, RMR is less than 0.08, GFI, NFI and CFI are all larger than 0.9 , so the model has a high degree of fit. In the confirmatory analysis of green innovation behavior, $\chi 2 \mathrm{P}$ value is 0.572 , more than 0.05 , RMSEA is 0.049 , less than 0.05 , RMR is less than 0.06 , GFI, NFI, CFI and so on are larger than 0.9 , so the whole model has high fitting degree.

\subsection{Results of Regression}

We used the multivariate regression to verify hypotheses. Table 1 showed the multivariate regression analysis results step by step. From the Model 1 and Model 2, we can see the model of green innovation behavior $\mathrm{R}^{2}$ from 0.049 up to 0.747 . HRMP overall explanatory force $\beta$ value is $0.799(p<0.01)$. This can explain the vast majority of corporate green innovation behavior. So, the hypothesis 1 is supported. The results of Model3 showed that only training, salary and performance is significantly $(\beta=0.378,0,327$ and $0.364, p<0.01)$, which means that hypothesis $2 \mathrm{~b}$, hypothesis $2 \mathrm{c}$ and hypothesis $2 \mathrm{e}$ were supported. The results of Model 4 and Model 5 showed that the organizational identity had significantly positive effect on the green innovation behavior $(\beta=0.729, \mathrm{p}<0.01)$.Therefore, hypothesis 3 was supported. 
Table 1. Results of Multivariate Regression Analysis.

\begin{tabular}{|c|c|c|c|c|c|}
\hline \multirow[t]{2}{*}{ Variables } & \multicolumn{3}{|c|}{ Organizational Identity } & \multicolumn{2}{|c|}{$\begin{array}{c}\text { Green Innovation } \\
\text { Behavior }\end{array}$} \\
\hline & Model 1 & Model 2 & Model 3 & Model 4 & Model 5 \\
\hline \multicolumn{6}{|l|}{ Control Variables } \\
\hline $\begin{array}{l}\text { The nature of the } \\
\text { enterprise ownership }\end{array}$ & -.037 & -.039 & -.039 & .094 & .119 \\
\hline $\begin{array}{l}\text { The operation period of } \\
\text { the enterprise }\end{array}$ & -.067 & -.064 & -.064 & -.019 & .029 \\
\hline $\begin{array}{c}\text { The number of } \\
\text { enterprises }\end{array}$ & .143 & -.010 & -.010 & .049 & -.037 \\
\hline \multicolumn{6}{|l|}{ Explanatory variables } \\
\hline HRMP Overall & $.799 * *$ & & & & \\
\hline Training & & $.378 * *$ & & & \\
\hline Salary & & $.327 * *$ & & & \\
\hline Performance & & .118 & & & \\
\hline Recruitment & & .127 & & & \\
\hline Employee participation & & $.364 * *$ & & & \\
\hline \multicolumn{6}{|l|}{ Mediation Variable } \\
\hline Organizational Identity & - & - & - & & $.729 * *$ \\
\hline $\mathrm{R}^{2}$ & .049 & .747 & .667 & .217 & .646 \\
\hline $\mathrm{F}$ & .945 & $36.795^{* *}$ & $14.793 * *$ & .925 & $17.589 * *$ \\
\hline
\end{tabular}

Then, we also use a hierarchical regression analysis method to test the mediating effect of organizational identity proposed in hypothesis 4 . The specific regression results are shown in Table 2 . From the change of $\mathrm{R}^{2}$, when we add the mediation variables "organizational identity", the regression model became more effective. The introduction of organizational identity makes the overall interpretation of green innovation behavior $\mathrm{R}^{2}$ rose from 0.747 to $0.836(\mathrm{p}<0.01)$. This means the hypothesis 4 was supported. It is worth noting that in the model 2 , when we added the human resource management practice, we found that the green innovation behavior became less significant. So, we verified the hypothesis 1 again.

Table 2. Mediation Regression Model of Organizational Identity.

\begin{tabular}{llcc}
\hline Variables & \multicolumn{3}{c}{ Green Innovation Behavior } \\
& Model 1 & Model 2 & Model 3 \\
\hline Control Variables & & & \\
The nature of the enterprise ownership & .069 & .089 & .094 \\
The operation period of the enterprise & -.021 & -.017 & -.018 \\
The number of enterprises & .047 & -.079 & -.091
\end{tabular}




\begin{tabular}{|c|c|c|c|}
\hline \multicolumn{4}{|l|}{ Explanatory variables } \\
\hline HRMP Overall & & $.799 * *$ & $.703 * *$ \\
\hline \multicolumn{4}{|l|}{ Mediation Variable } \\
\hline Organizational Identity & & & $.284 * *$ \\
\hline $\mathrm{R}^{2}$ & .049 & .747 & .836 \\
\hline $\mathrm{F}$ & .945 & $36.795^{* *}$ & $39.853 * *$ \\
\hline
\end{tabular}

\section{Discussion}

Our results have important implications for manufacturing enterprises. Enterprises need to combine their own practical implementation of the green innovation to enhance the human resources management strategy. In the era of low-carbon economy, enterprises should convey the green, environmental protection, low-carbon, energy-saving concept to employees. Enterprises can achieve the entire enterprise green strategy driven by the green concept of all employees. Next, our finding is that green training and green salaries of enterprises have a significant impact on green innovation, so focusing on greening in training and compensation can improve green innovation. Enterprises should strengthen green environmental training and build a compensation system that includes incentives for green innovation. In the training content, enterprises need to train their employees in environmental policy, environmental performance, environmental management and environmental knowledge. In terms of compensation, enterprises should give green compensation and recognition to the employee who have a green behavior. Furthermore, our results suggest that improving the participation of employees and their organizational identity can help improve the green innovation behavior. The object of green human resource management is employees. So, it is helpful that improving the organizational identity of employees and increasing the chance of employees' participation to promote the improvement of green innovation. Another implication is that enterprises should not ignore the recruitment and performance which did not been verified in the regression analysis. Because recruitment is one of a channel for employees to enter the enterprise, green recruitment can identify and access to environmentally friendly employees, thereby enhancing the green business innovation. The combination between performance and salary can also improve the green innovation behavior of enterprises.

As in most research, our studies have limitations. First, enterprise green innovation is a more complex research variable, we cannot measure all items. Second, In the selection of samples, because of limited to the ability to investigate, we maybe miss an important representative of the enterprise, the study sample selection is not a fullscale. We call for future research to study the establishment of green innovation index system and the selection of intermediary variables. Future research seeking to study 
whether human resources management can improve the green innovation and how to improve the green innovation behavior by some mechanism.

\section{Conclusion}

This paper uses a variety of methods such as questionnaire survey, multivariate regression model to do empirical research on the mechanism of human resource management influencing corporate green innovation behavior. Our results show that the background information of the enterprise as the control variables is not related to the organizational identity of the employees and the green innovation behavior. Furthermore, our research also aims to significant positive correlation between human resource management practice and organizational identity. But only training, salary and employee participation have a significant positive impact on the employee's identity. Others assumptions did not been validated. Thus, our research enriches the results of the impact mechanism of human resource management on the green innovation of enterprises. We contribute to the research on human resource management as outcome variables and the shortage of empirical research.

Acknowledgements. This work was supported by the soft science project of Science and Technology Department in Shaanxi province (2017KRM091).

\section{References}

1. Ashforth, B.E., Mael,F.: Social identity theory and the Organization. Academy of Management Review,14, pp. 20-39, (1989).

2. Bai Bing-quan, Gao Juan: Enterprise Human Resource Management under the Concept of "Green Harmony" [J]. China Leadership Science, 5, pp. 23-25, (2014).

3. He Ai-Zhong, Du Jing, CHen Mei-li: Effects of Green Cognition and Green Emotion on Green Behavior in Retail Enterprises [J]. Chinese Soft Science,(04), pp. 117-127, (2013).

4. Li Wan-hong, Bi Ke-xin, Cao Xia: Effects of Environmental Regulation Tools on Green Technology Innovation of Manufacturing Enterprises - Taking Papermaking and Paper Products Enterprises as an Example [J]. Systems Engineering, 10, (2013).

5. Pan Chu-Lin, Tian Hong: Study on the Impact of Forward-looking Environmental Strategy on Green Innovation Performance of Enterprises - The Chain Mediation Role of Green Intellectual Capital and Absorptive Capacity [J]. Business Review, (07), pp. 85-93, (2016).

6. Renwick, D. W. S. R., Redman, T., Maguire, S.: Green human resource management: a review and research agenda [J]. International Journal of Management Reviews, (10), pp. 114, (2012).

7. Sui Jun, Bi Ke-xin, Yang Zhao-jun et al.: Influencing Factors of Innovation Performance of Green Innovation System in Manufacturing Industry - Based on the Perspective of Transnational Corporation Technology Transfer [J]. Journal of Scientific Research, 33(3), pp. 440-448, (2015).

8. Wan Xi: A Study on China's Green Human Resource Management from the Perspective of AMO Theory - A Micro-Research Perspective [J]. China Human Resource Development, 10: pp. 9-13, (2012). 
9. Wei Jin-xiu: Study on Green Human Resource Management of Hotel [D]. Qingdao: Qingdao University, (2006).

10. Westbrook, R A, Oliver, R L.: The Dimensionality of Consumption Emotion, Patterns and Consumer Satisfaction[J].Journal of Consumer Research,18(6):84-91 (1991).

11. Wu Guo-ciang: The influence of green supply chain integration and environmental uncertainty on green innovation in Taiwan's IT industry [J]. Supply Chain Management: An International Journal. (5), (2013).

12. Yang Guang: Green Human Resource Management - The Greening of Human Resource Management [J]. Management Review, 15, pp. 8-10, (2003).

13. Yang Zhao-jun: Effects of FDI on the Innovation of Green Process in China's Manufacturing Industry and Its Spillover Effect [D]. Harbin Engineering University, (2013).

14. Yi Sheng, Xue Qiu-zhi: Green Supply Chain Management and Green Innovation: An Empirical Study Based on Chinese Manufacturing Enterprises [J]. Science and Management, 37 (06): 103-110, (2016).

15. Zhu Cheng-liang: China's Manufacturing Industry Green Innovation Performance and Industry Differences [J]. City and Environment Research, (01): pp. 73-84, (2017). 